\title{
Determinates of Accounting Software Choice: An Empirical Approach
}

\author{
Oladipupo Muhrtala ${ }^{1, *}$, Mathias Gboyega Ogundeji ${ }^{2}$ \\ ${ }^{1}$ Department of Accounting and Finance,Elizade University, Ondo-State, Nigeria \\ ${ }^{2}$ Mathias Gboyega Ogundeji \& Co. (Chartered Accountants and Tax Practitioners), 72/82, Kudirat Abiola Way, Suite A1, Humuani \\ Shopping Mall, Oregun, Ikeja, Lagos-Nigeria \\ *Corresponding Author: oladipupotijani@gmail.com
}

Copyright $(2014$ Horizon Research Publishing All rights reserved.

\begin{abstract}
The purpose of this paper is to examine the primary determinants of commercial accounting packages acquisition specifically amongst non-financial quoted companies, in Nigeria. The study analyses accounting software deployment decision using a sample of 178 participants across 5 industries listed on the Nigerian Stock Exchange. A logistic regression model was performed in order to determine which of the factors has the greatest influence. The authors found factors such as operational, commercial, strategic, technical and security considerations as primary determinants of accounting software deployment. In addition, the study also revealed that all companies surveyed have implemented at least one type of commercial accounting package. Special purpose and generalized systems were however found to be most common applications across surveyed firms. This study is the first of its kind in Nigeria to examine the determinants of accounting software deployment with particular reference to quoted companies in the non-financial firms.
\end{abstract}

Keywords Accounting, Software, Non-Financial, Nigerian Stock Exchange, Commercial, Applications, Determinants, Deployment, Systems, Nigeria

\section{Introduction}

Research in academia and practice has exceedingly emphasized the changing role of the accounting function resulting from the advent of information technology over fifty years ago. The adoption of IT tools and techniques has substantively enhanced corporate reporting responsibility as it continued to enrich access to timely, qualitative and comprehensive information. Corporations the world over irrespective of size, type, structure or stage of development has identified with the role of IT as enabler of industry and commerce. This backing provided by IT has also been accompanied by its prominence in professional accountancy practice. It is increasingly becoming impossible to overemphasize these benefits, whether quantitative or qualitative amongst which are improved staff motivations, enhanced information processing capability, cost reduction and displacement, operational efficiency, increased speed of data transfer engendering competitive advantage and ultimately increasing profitability (Moghaddam et al., (2012) [13]. The evolvement of IT has increased the efficiency of financial transactions processing as the adoption of commercialized packages generated improvement to quality and quantity of information made available to management for decision making (Collins, 1999; Fisher \& Fisher, 2001) [4]. In addition, the robustness of IT equipment and facilities developed overtime also necessitated the assembling of integrated applications by software manufacturers (Jones, 2002) [8]. The use of accounting software in managing accounting information evolved nearly thirty five years ago and has in recent times become an integral part of most organizations operations (Wen et al., 2012) [19]. Although the degree of implementation differs by business class, size and industry, their deployment has become integral to almost every corporate survival strategies. The acquisition of software to support processing of financial transactions in today's business is essential and its success depends largely on feasibility of alignment with corporate, business or operational level strategies. The prohibitive cost of software development, relatively low cost of commercial applications, growing demand from business that are too small to afford in-house systems development staff, the trend towards organizational units restructuring into distributed data processing environment, (Hall, 2011) [7] and availability of software solutions in generalized IT resource markets has made the option of acquisition a preferred course (Finkelstein \& Farbey, 2004) [6].

The need to align IT and corporate strategy is a key success factor in any competitive advantage seeking situation. Nevertheless, the deployment of IT resources does not come without prohibitive cost implications. Whether by way of complete in-house developed solutions or commercial packages such as turnkey Systems, Backbone systems, Vendor-Supported solutions or ERP systems, 
empirical evidence suggest that corporations invest heavily to these intangible assets. Some ERP solution cost well over $\$ 100$ million while the cost of customized systems built from scratch through in-house systems development activities substantially higher. The challenge however is not the initial costs of installation, training or the continued cost of vendor support, data conversion, backup or other associated costs. The concern is mostly associated with operational and strategic implications of making the wrong choice of accounting software at the onset and subsequently taking decision to engage in system conversions few years down the line rather than mere upgrades or fixes. Little evidence might suffice within this context. Period immediately preceding the industry consolidation in Nigeria, specifically between 2004 and 2006, majority of the banks engaged in systems conversion by switching completely from existing applications while others simply upgrade their platforms to absorb capacity expansion due from the consolidation process. Not only had such companies sustained great financial losses, they have also had to grapple with operational, technical and overall business challenges of such decisions asides struggling to cope with significant strategic implications on their business due to their inability to spend considerable time researching all aspects of these applications prior to engaging the vendors (Abu-Musa, 2005) [1]. During these periods, there were massive ill experiences by customers as a result of inability to meet up with routine transactions efficiently. Without doubts there are also psychological, social and economic implications of such occurrence. Whenever organizations are required to decide on strategic positioning, it is important they get it right in good time, research have contended that selecting a software could be the most important purchase in the life of an organization hence should be treated as a key strategic decision (Simkin, 1992) [15].

The decision to acquire or change accounting information system is an important undertaken. An entity might consider an accounting software wherein it is experiencing growth or even downsizing or in cases where it require additional complex reporting system. It is appropriate to evaluate not just the key indicators prompting such changes but all requirements that must be met under the new system. Prior to acquisition, the entity often consider immediate accounting information requirements. This is in cognizance with size of operations, complexity of financial transactions processing, type, number as well as reporting frequency, specific information requirements, and interfacing systems integration. There might also be the need to decide on factors essential for successful conversion prior to evaluating accounting software packages. Such would likely involve routine activities as training, setting up accounts charts, existing data conversion, interfaces with existing platforms, and even consultation with other experts. Although in recent past, works in accountancy practice on the role of IT in financial transactions processing has been remarkable, there seem to be lack of solid empirical view in the literature. A number of studies have embraced the implications of technology tools on the accounting function, only very few amongst them in some manner have been empirical and by extension had their focus on other distinct areas rather than examining factors responsible for accounting software choice even though this concept is obviously strategic in terms of the role of accounting in corporate decision making. By implication, this study seeks to offer empirical indication to critical success factors in accounting software deployment following the widespread use of commercial accounting packages. The purpose is to assess the validity and reliability of a theoretical model based on determinants of accounting software choice proposed by Abu-Musa (2004) [1]. This study focused on non-financial services companies listed on the Nigerian Stock Exchange. The aim is to identify the factors which were considered most significant when deploying their various applications. This is first of its kind as the authors are unable to identify any empirical research in Nigeria which examined the determinants of the choice of accounting software in the literature.

We employed a survey approach in collecting evidence that would suffice in this study across companies listed in the non-financial industries amongst conglomerates, construction and real estates, consumer foods, healthcare, and general services.

\section{Literature Review}

\subsection{Theoretical Framework}

To provide theoretical support for this study, we build a framework on the emergent process theory as propounded by Markus and Tanis (1997) [12]. The theory was found on providing description on the value creating effects of IT. In order to comprehend the realization of enterprise systems adoption, the theory tries to provide clarity on whether IT creates value on business or not by contributing three key points. The first claim is that in their prototype, the conditions necessary to achieve success in superior technology information assets deployment are not always adequate for business success and that there are intermittent happenings capable of distracting intended accomplishments in IT investments. These events usually may include complex attitudes and changes in customers' demand, technology obsoleteness, and dynamism portend by the external environment usually outside the immediate control of the entity. Hence the chance of value creation capability of IT to business is greatly subjected to probabilities. The theory also describe the process of IT deployment as an interlinked model consisting of the stages convoluted in typical plan of systems development, implementation, and post implementation review the conclusion of one segment forming the input of the other thereby creating an intertwined success or failure interdependencies. Additionally, due to the involvement of various project team members the success of business enabling value creating technologies and tools is also influenced by communication challenges across the 
phases involved. The third point emphasized complexities associated with the connections flanked by undertakings in the phases and the exterior uncontainable elements, which are highly likely to distract project focus. Similarly, there may be ineffective harmonization of schedules causing avoidable interruptions and ultimately leading to unsuccessful outcomes.

This theory is consistent with the views of Markus and Tanis (1997) [12] when they opined that the usefulness of a theory depends upon relevance to practitioners' motivated behavior and goals, and its significance to extraneous factors in cognizance to fact fitness. This theory is in perception with the need for organizations to consider the choice of selecting accounting software as a strategic decision in terms of flexibility of the application to meet both specific and future requirements. In essence, this would provide opportunity to capture top management assurance in a strategic-fit decision of technology adoption rather than tactical and operational requirements alone (Abu-Musa, 2005) [1]. Consequently, the initial expectation is for an organization to reflect on its strategic focus. Factors such as possible future capacity expansion, company's primary value drivers, future diversification, integration, reorganization, restructuring as well as predictions of likely changes in consumer demand generators amongst others are key considerations.

\subsection{Information Technology and Accounting: Empirical Evidences}

The purpose of financial accounting is to provide financial information about an economic entity for that can be used to plan and control the operating and finance decisions of the entity. Although these financial information were hitherto prepared at extensive intervals, the advent of computerization and subsequent development of accounting software has made possible the preparation and presentation of financial information at littler intervals. In recent times, financial reports may be made available as often as may be required for management decision (Law \& Coulmas, 2010) [10]. Technology sophistication has now engendered real-time financial transactions processing platforms (Law \& Coulmas, 2010) [10] as the use of traditional accounting exercise have almost been completely replaced by real time systems (Rezaee, Ford \& Elam, 2000) [14]. It has also been argued that in contrast to periodic financial performance reporting, technology would pave way for new standards that will allow for uninterrupted measurement and reporting of transactions for users of financial information (Mattingly, 2001)[11]. This has been the subject of the XML-based XBRL. Eventually, transactions shall cause to be entered and recorded as business processes continue and reports made available instantaneously providing a base for progress tracking (Law \& Coulmas, 2012) [10]. The distribution of specialized audit software has also replaced labor with IT and cause significant change in professional audit team members (Banker, Chang \& Kao, 2002) [3]. The level of computerization of accounting system differs across industry, business size, class, and mode of operation. Studies have shown that the rate of software adoption by small and medium enterprises is lesser than 30 percent as compared to large businesses of more than 90 percent due to their structural, financial and organization culture differences (Wen et al., 2012) [19].

The decision on what accounting software to adopt is essentially that of senior management since they hold primary responsibility for IT, the involvement of accountants and auditors should however be significant since they are responsible for financial transactions processing and ultimately corporate reporting. Usually in practice, committees are established amongst which they are included. Where systems are designed in-house, as major stakeholders their expertise are principally required during the process to provide technical expertise on accounting rules, procedures and specific compliance requirements. They must also ensure monitor adherence to specific documentation standards and verify systems control adequacy during detailed design and implementation phases (Hall, 2011) [7]. Wherein such accounting applications are web-enabled to support customers, partners and suppliers of companies, their input is often minimal at this stage. The choice of accounting software systems may arguably be related to what one is likely to seek in a spouse. Everyone wants some sense of commitment (software output accuracy), one who grows with them (software scalability), who could be treasured and nurtured through sickness (fixes), and in grow with in good health (upgrades). Such candidate must possess dependable intimacy (confidentiality), be around to share current needs and be easily adapted to share future financial and non-financial desires and aspirations (availability), and keep family secrets on a need-to-know basis only (integrity) at all times (Jones, 2002) [8]. The fragmentation of commercial packages market increasingly makes difficult the decision (Mattingly, 2001) [12]. Perhaps most organization concentrate on satisfying short term requirements on choosing commercial applications at the expense of future needs for financial and non-financial information requirements (Collins, 1999) [4] mostly due to initial set-up cost implications. The expectation however is that both short and long term requirements should be taken into cognizance in deciding what software to adopt.

Organizations obtain significant benefits in the use of IT in financial transactions processing. Even in professional accountancy practice, firms have been transformed with advancement in audit software and knowledge sharing applications (Banker et al., 2002) [3]. A number of studies have used survey questionnaire to identify the relationship of IT to accounting systems. In a study exploring the impact of IT implementation on public accounting firms' productivity, Banker, Chang and Kao (2002) [3] examined 5 offices of an international firm of public accountancy practice that made large investment in computerized processes. Using both qualitative and quantitative information obtained from the research sites over a 24 months observation obtained via 
survey instrument, the study after a parametric and non-parametric estimation methods across relevant variables revealed that there were significant improvements in productivity providing support for the value of audit automation and knowledge-sharing applications represented by improved increased revenue and operational efficiency. The results of qualitative information also suggested that electronic presentation of information assists audit professionals in decision making. Information obtained through knowledge sharing databases similarly provides critical support for audit decisions as deployment of groupware applications facilitates effective collaboration and improve quality of decisions.

Moghaddam et al., (2012) [13] assessed the impact of technology on accounting scope in Iran on a survey approach. With the aid of questionnaire and interview sessions, the study found relevant implications of IT to transactions processing. The authors reported that the adoption of accounting applications enabled automated transformation of documents into simple journal and ledger as book-keeping was eliminated and subsequently accuracy of accounting processes improved considerably. There was also improvement in costing methods in the light of activity-based techniques, cost reduction and decline in turnaround time for reports generation. In an attempt to study more complex and customized accounting applications Khattak et al., (2012) [9] examined critical success factors affecting enterprise resource planning implementation in Pakistan enterprises. ERP are essentially prewritten systems characterized by integrative capability and in some cases applied as turnkey solutions (Hall, 2011) [7]. Using a survey approach though limited to four organizations, the study found several factors responsible for successful implementation of the software. Factors that received highest consideration were selection of effective project manager, staff training adequacy, user support, change management culture and programs. Others include clearly specified project goal, business process reengineering/minimal customization, user friendliness, and vendor support. Although ERP systems enable comprehensive operations integration they are often considered as costly to implement and maintain with high failure rates and budget overrun (Shang et al., 2002) [16].

In a related literature Wen et al (2012) [19]observed the adoption of accounting software in the fastest growing member of the BRICS nations when they investigated the extent of accounting software adoption amid small and medium agro based enterprises in Heilongjiang. Using a number of independent variables the result observed low rate of accounting software adoption amongst SME's in China. However, while the age of managers was found to be negatively correlated to software adoption, the number of accountants engaged was positively related. Furthermore, accountants' level of computer knowledge were found to be an important consideration in deciding whether or not to embrace accounting software in financial transactions processing by agro based enterprises in Heilongjiang.
However, the study conclusively emphasized the need to acquire applications with adequate security features. Although the study shared similar audience with this, its concentration however was the extent of software adoption rather than determinants of choice of software selection. One of the most important conclusions is that these studies have used survey approach to evaluate the impact of IT on financial transactions processing. However, the authors are unable to identify with any of them conducting an assessment on factors determining the choice of software selection.

\section{Research Questions}

In furtherance with the issues raised in the literature review necessitating further exploration of accounting software technology on financial transactions processing this study is designed to provide answers to the following research questions based on evidence obtained from the companies surveyed:

i. What is the level of accounting software adoption amongst non-financial services companies in Nigeria?

ii. What types of commercial packages are most common amongst listed entities in Nigeria?

iii. What factors were considered most significant by these companies during their initial deployment of accounting software systems?

\section{Methodology}

The absence of empirical literature in Nigeria in the area of accounting software adoption necessitated our approach to this study. In the first instance, we provide an experiential assessment of the mathematical model proposed by Abu-Musa (2005) [1] in rationalizing the process of selecting accounting software packages. Subsequently the elements proposed in the study were adapted with little modifications to suit the particular circumstance of the working environment. The Survey population comprises of all companies quoted under the non-financial services sector in the first-tier securities market of the Nigerian Stock Exchange and this list include conglomerates, construction and real estates, consumer foods, healthcare, ICT, Industrial goods, natural resources, oil and gas, and general services. The purposive sampling technique was however employed with the sample consisting of subjects amongst conglomerates, construction and real estates, consumer foods, healthcare, general services in Lagos State, which was considered a good representation due from the concentration of business, and commercial activities in the city. The sample is made of IT steering committee members' essentially senior management of responding organizations who hold primarily responsible for IT and Business System strategies. The initial sample size for each group was 
targeted at forty (40). The choice of forty (40) is guided by literature on statistical tests sample frame averaged at thirty (30) (Balian, 1994; Denscombe, 2003) $[2,5]$ as primary data was obtained via carefully constructed questionnaire designed to obtain information on demographic details and also provide feedback to research questions suggested in the study.

\subsection{The Survey}

The structure of the survey instrument was adapted from the model as proposed by Abu-Musa (2005) [1] to evaluate the determinants of accounting software choice. It however included some other questions, which may be peculiar to the study environment, as well as other filter questions considered relevant by the authors. The instrument was also divided into two (2) sections. Accordingly, the first section captured information on respondents' demographic details whereas the second consisted of questions gathering evidence on respondents' views as regards primary considerations in their choice of accounting software. The instrument made use of a five (5) point Likert type scale based on metric and dichotomous questions to provide the platform sufficient in analyzing the variables under study and to assess specific circumstances (Vagias, 2006) [18]. In this regard each of the statements in the second part of the instrument was placed on a score between one (1) and five (5). A score of one (1) represented "not a priority" with the statement, while five (5) denoted "essential". In order to verify internal consistency, a pilot survey was conducted from which an internal consistency was estimated using Cronbach's Alpha coefficient arriving at a value of 0.793 . All the items were also evaluated leading to a sampling error calculated at 8.74 percent and consequently considered acceptable due to the absence of any previously recognized parameters under the enquiry. Survey tabulations were generated in accordance with the type of questions being investigated under descriptive analysis. Lastly, the filter questions were also adopted in estimating two variables in the study, the predispositions obtained as well as respondents' attitudes in the face of the survey peculiarity. A combination of descriptive and inferential statistics was adopted. While descriptive analysis was used to determine the level of computerization as well as the classes of commercial packages most common across industries surveyed, inferential statistics in particular a logistic regression was performed to assess the main factors considered in software deployment. Analyses were carried out using Statistical Package for Social Sciences, (SPSS Windows Version 18.0, 2009). The field work was carried out between May and July 2013.

\subsection{Description of Variables}

For clarity of variables proposed in verifying the answers to the research questions several factors were named and interpreted accordingly. These elements made of determinants of commercial accounting software choice were afterwards delineated into five (5) major components explicitly commercial, technical, operation, security and strategic considerations. The synopsis is as provided in Table 1.

Table 1. Analysis of Principal Components

\begin{tabular}{|c|c|}
\hline Factors & Questionnaire Item (Variable) \\
\hline Operational & $\begin{array}{c}\text { 6i: Support for accounting and reporting } \\
\text { 6ii:Account Systems Structure } \\
\text { 7ii:Multi-Currency Platform } \\
\text { 7iii:Product Modules (support for batch and } \\
\text { real time processing) } \\
\text { 8iii: Transactions Processing/limiting } \\
\text { characteristics } \\
\text { 9i: Event-Triggered Reporting and reduced } \\
\text { processing errors } \\
\text { 9ii:Automated ledger reconciliation and Data } \\
\text { Validation } \\
\end{array}$ \\
\hline Commercial & $\begin{array}{c}\text { 10i:Web-Features and e-commerce } \\
\text { 10ii:Price of core modules } \\
\text { 10iii:Other Initial Acquisition cost } \\
\text { 10iv:Maintenance cost } \\
\text { 10v:Multipleuser modules platform } \\
\text { 10vi:End-used reference/Large Installed Base } \\
\text { 10vii:Vendor Reliability } \\
\end{array}$ \\
\hline Technical & $\begin{array}{c}\text { 11i: Database support } \\
\text { 11ii:Reseller Programs } \\
\text { 11iii: Scalability } \\
\text { 11iv:Link to third party } \\
\text { 11v:Programming Language } \\
\text { 11vi:Hosting } \\
\text { 11vi:IT environment and Infrastructure } \\
\text { 11vii:Technical Support }\end{array}$ \\
\hline Security & $\begin{array}{c}\text { 4i:Internal Logical Access Security } \\
\text { 4ii:Web-enabled/e-commerce linked security } \\
\text { 4iii:strong identification and authentication } \\
\text { procedures }\end{array}$ \\
\hline Strategic & $\begin{array}{c}\text { 12iii:possible future business expansion } \\
\text { 12ii:Partnership and Strategic Alliances } \\
\text { 12iv:Multi-Business Units Integration } \\
\text { 12v:Likely Franchise Arrangements } \\
\text { 12vi:Future Mergers \& Acquisitions } \\
\text { 12vii:Multi-Product and/or service expansion } \\
\text { arrangements }\end{array}$ \\
\hline
\end{tabular}

In order to provide answers to the questions raised in the study results were sectionalized accordingly. Section 5.1 and 5.2 provided answers to research questions one (1) and two (2) through descriptive analysis while section three (3) attempted through logistic regression to provide explanations into the primary determinates of accounting software choice by surveyed firms.

\section{Results of Data Analysis and Interpretation of Results}

Subjects response were grouped according to industries and feedback from questionnaire distribution showed that from the two hundred (200) copies administered, only one hundred and seventy eight (178) copies were returned wholly completed and verified adequate for analytical purpose. This 
response of eighty nine (89) percent for all groups was successively used as input to the research questions with its distribution provided in Table 2.

Table 2. Survey Instrument Distribution

\begin{tabular}{|c|c|c|c|}
\hline $\begin{array}{c}\text { Responding } \\
\text { Groups }\end{array}$ & $\begin{array}{c}\text { Instrument } \\
\text { Distribution }\end{array}$ & $\begin{array}{c}\text { Number } \\
\text { Retieved }\end{array}$ & $\begin{array}{c}\text { Proportion of } \\
\text { Response }\end{array}$ \\
\hline $\begin{array}{c}\text { Construction and } \\
\text { Real Estates }\end{array}$ & 40 & 36 & $90.00 \%$ \\
\hline Consumer Foods & 40 & 29 & $72.50 \%$ \\
\hline General Services & 40 & 39 & $97.50 \%$ \\
\hline Health Services & 40 & 38 & $95.00 \%$ \\
\hline Health care & 40 & 36 & $90.00 \%$ \\
\hline Aggregate & 200 & 178 & $89.00 \%$ \\
\hline
\end{tabular}

\subsection{Level of Accounting Software Deployment}

The outcome of descriptive analysis revealed that all companies surveyed have acquired competing commercial accounting packages with distinct features in accordance with needs of individual organizations. Although there are several intangible factors capable of complicating the process of software deployment generally it is pertinent to mention that the choice of going complete or partial computerization is also the responsibility of senior management. According to the survey instrument, one hundred and thirty seven (137) respondents (77 percent) indicated that their accounting transactions processing systems were fully computerized while forty one (41), (23 percent) combined manual and computerized systems. Therefore we might conclude that non-financial sector companies contribute significantly to increasing trend of computerized accounting systems in developing economies like Nigeria. This is also an evident that business managers support the role of IT as an enabler of financial transactions processing. This result complements the survey on ERP systems by Spathis and Constantinides (2004) [17] as reported that the adoption of prewritten systems as turnkey applications enable changes in accounting processes.

\subsection{Classes of Commercial Software Options}

Concerning the types of accounting applications common amongst companies surveyed, respondents were required to indicate from a list of commercial packages including turnkey systems (general accounting systems, special purpose systems, and office automation tools); Backbone systems; Vendor support systems; and ERP systems. Cross tabulation result indicated that accounting software users across all groups accommodating special-purpose applications were 34 percent. Of this, 94 percent (32) is from the healthcare sector while 6 percent (2) minority were reported under construction and real estates. This could be attributed to the highly industry-specific procedural inclination attributed to such systems (Hall, 2011) [7]. In addition, 37 percent were users of general accounting system. These systems are results of mass producing powerful applications offering greater flexibility as compared to special purpose systems. In addition to non-standardized nature of these systems they also provide users the privilege to purchase specific capable of satisfying precise financial transactions processing requirements (Hall, 2011) [7]. Users of such software as evidenced from the questionnaire retrieved were under construction and real estates (19 percent), conglomerates (16 percent), and general services ( 2 percent) industries. This result is an indication of the likelihood of popularity of turnkey solutions over backbone, vendor-support and ERP systems in Nigeria in that 71 percent of respondents uses at least one class of turnkey systems (general accounting systems, special purpose systems, or office automation tools). The remaining 29 percent were found across consumer foods (16 percent), conglomerates ( 6 percent) and general services ( 7 percent) deploying either of backbone, vendor-support or ERP systems. This suggests other considerations beyond immediate accounting and reporting quality requirement of individual organizations influence accounting software deployment.

\subsection{Determinates of Accounting Software Choice}

Under the questionnaire item determinates of software choice, the importance of operational, commercial, technical, strategic and security considerations was highlighted under the result of logistic regression performed to establish the factors with the greatest incidence in selecting commercial accounting applications. For this purpose, the adoption of commercial accounting software was identified as the dependent variable and the independent variables were the five (5) identified factors indicated in Table 1. In this way, the five (5) independent variables were obtained corresponding to their relative questionnaire items (variables). Subsequently the optimal independent variables that presented the most significant relationship with the dependent variable were: (a) operational, (b) commercial, and (c) security considerations and (d) strategic. Table 3 detailed the result of logistic regression performed. Although, technical factors did not emerge as a relevant variable this result accord with the expectations of the authors and the recommendations suggested by Abu-Musa (2005) [1], strategic considerations also emerge as a relevant explanatory variable for commercial accounting package usage, due from its significant implications for business competitive stance. Nevertheless, factors of subjective character (operational, commercial and security considerations) were found to be of utmost significant (see Table 3). Consequently, propensity in the choice of selecting accounting software is greater with operational $(\operatorname{Exp}(\mathrm{B})=$ 1.972); commercial $(\operatorname{Exp}(B)=5.576)$; and security $(\operatorname{Exp}(B)$ $=0.548)$ considerations. The result of this study agrees substantially with the findings of Wen et al. (2012) [19], when they investigate the level of software adoption amongst 
small and medium enterprises in China. The result evidenced that more than 90 percent of large companies in China make use of commercial accounting packages. Our findings is also consistent with Khattak et al., (2012) [9] in their examination of critical success factors affecting ERP implementation in Pakistan enterprises. Factors that received highest consideration were selection of effective project manager, staff training adequacy, user support, change management culture and programs. Others include clearly specified project goal, business process reengineering/minimal customization, user friendliness, and vendor support.

\subsection{Conclusion and Recommendation}

One of the most critical decisions in today's business is the choice of accounting system. More often managers primarily focus on short-term benefits at the expense of long-term strategic considerations. Without doubt, elements such as improved real-time access to organizations critical information assets, financial and reporting information, and greater control over transactions processing in business are indispensable. However, the need for the right type of accounting solutions that meets possible future capacity expansion and accommodates increased number of users, customers; other database contents and business intelligent data are as indispensable.

This study attempted to investigate the primary determinates of commercial packages selection amongst non-financial sector companies in Nigeria. The results suggest that the deployment of accounting software by companies is principally driven by operational, commercial and security concerns. This indicates that short term factors hold ace as underlying factors for software selection against strategic requirements. This further confirms that tactical and business approaches take precedence over corporate strategic considerations when business managers take decision on business process solutions.

Business executives must begin to take cognizance of non-quantifiable possible business enlargement such as strategic alliances, mergers and acquisitions, franchise arrangements capable of generating further capacity expansion and other likely future arrangements. Managers should begin to consider the prohibitive cost of systems conversions and change-overs when the right decisions are not taken at initial systems deployment. Rather than engaging in overall systems change, they must endeavor to engage the right decisions to deploy accounting systems possessing requisite expandable and upgrade capabilities as their businesses grows. Accounting systems that satisfy current and future business needs are the right tools in today's business

It is expected that future research could examine unique considerations in selecting specific commercial applications such as turnkey solutions, vendor specific applications, ERP and Backbone systems. In addition studies may investigate what companies in the financial services industry considers as overriding factors in choosing accounting systems.

Table 3. Results of the Final Logistic Regression Model Output

\begin{tabular}{|c|c|c|c|c|c|c|c|}
\hline & \multirow{2}{*}{$\mathrm{B}$} & \multirow{2}{*}{ S.E. } & \multirow{2}{*}{ Wald } & \multirow{2}{*}{ Sig. } & \multirow{2}{*}{$\operatorname{Exp}(B)$} & \multicolumn{2}{|c|}{$95 \%$ C.I.for $\operatorname{EXP}(B)$} \\
\hline & & & & & & Lower & Upper \\
\hline Operational & .679 & 0.350 & 3.760 & 0.000 & 1.972 & 0.993 & 3.017 \\
\hline Commercial & .713 & 0.478 & 12.854 & 0.000 & 5.576 & 2.714 & 14.157 \\
\hline Technical & .755 & 0.562 & 7.871 & 0.052 & 0.408 & 1.245 & 4.802 \\
\hline Security & .192 & 0.254 & 7.812 & 0.000 & 0.548 & 4.987 & 9.082 \\
\hline Strategic & .870 & 0.259 & 6.098 & 0.000 & 0.624 & 2.518 & 11.034 \\
\hline Constant & -0.896 & 0.334 & 7.093 & 0.007 & 0.308 & & \\
\hline
\end{tabular}




\section{REFERENCES}

[1] Abu-Musa, A. "The Determinates of Selecting Accounting Software: A Proposed Model", The Review of Business Information Systems, Vol. 9 No. 3, pp. 85-110. 2005.

[2] Balian, E. "The Graduate Research Guidebook: A practical Guide to doctoral/masters Research", Maryland: University Press of America. 1994.

[3] Banker, R., Chang, H., and Kao, Y. "Impact of Information Technology on Public Accounting Firm Productivity", Journal of Information Systems, Vol. 16 No. 2, pp. 209-222. 2002.

[4] Collins, J. "How to Select the Right Accounting Software", Journal of Accountancy, New-York, Vol. 188 No. 2, pp. 61-69. 1999.

[5] Denscombe, M. "The good research guide for small-scale social research projects. ( ${ }^{\text {nd }}$ Ed.)", Maidenhead-Philadelphia, Open University Press. 2003.

[6] Finkelstein, A., and Farbey, B. "Software Acquisition: A Business Strategy Analysis", Journal of Information Technology, Vol. 6 No. 8, pp. 54-62. 2004.

[7] Hall, J. "Construct, Deliver, Maintain Systems Project", Dewey, R. (Ed.), Accounting Information Systems, Centage Learning, Mason, OH, pp. 633-636. 2011.

[8] Jones, R. "Spotlight on midlevel ERP Software", Journal of Accountancy, New-York, Vol. 193 No. 5, pp. 24-47. 2002.

[9] Khattak, M., Yuanguan, S., Irfan, M., Khattak, R., and Khattak, S. "Examining Critical Success Factors Affecting ERP Implementations in Enterprises of Pakistan", Interdisciplinary Journal of Contemporary Research in Business, Vol. 3 No. 10, pp. 606-632. 2012.

[10] Law, M, and Coulmas, N. "Exploration of Accounting Software Usage: An Empirical Research Applied On The Pennysylvania Home Building Industry", International Journal of Management and Information Systems, Vol. 14 No.

1, pp. 29-34. 2010.

[11] Mattingly, T. "How to Select Accounting Software", The CPA Journal, Vol. 71 No. 11, pp. 325-335. 2001.

[12] Markus, M., and Tanis, C. 'Learning from Adopters' Experiences with ERP: Problems Encountered and Success Achieved", Journal of Information Technology, Vol. 15, pp. 245-265. 1997.

[13] Moghaddam, A., Baygi, S., Rahmani, R., and Vahediyan, M. "The Impact of Information Technology on Accounting Scope in Iran", Middle-East Journal of Scientific Research, Vol. 12 No. 10, pp. 1344-1348. 2012.

[14] Rezaee, Z., Ford, W., and Elam, R. "Real-Time Accounting Systems", The Internal Auditor, Vol. 57 No. 2, pp. 62-67. 2000.

[15] Simkin, M. "Decision Support Tools for Choosing Accounting Software", The CPA Journal, Vol. 6 No. 4, pp. 74-82. 1992.

[16] Shang, S., and Seddon, P. "Assessing and Managing the Benefits of Enterprise Systems: The Business Managers' Perspective", Information Systems Journal, Vol. 12, pp. 271-299. 2002.

[17] Spathis, C., and Constantinides, S. "Enterprise Resource Planning Systems' Impact on Accounting Processes", Business Process Management Journal, Vol. 10 No. 2, pp. 234-247. 2004.

[18] Vagias, W. "Likert-Type Scale Response Anchors", Clemson International Institute for Tourism \& Research Development, Department of Parks, Recreation and Tourism Management. Clemson University. 2006.

[19] Wen, J., Matsumura, H., Mohamed, E., and Huang, J. "Adoption of Accounting Software by Agro Based Enterprises in China - The Case of Medium and Small Scale Privately Owned Enterprises, State-Owned Farms and Agricultural Cooperatives", International Journal of Research in Engineering, IT and Social Sciences, Vol. 2 No. 2 , pp. 82-99. 2012. 